\title{
REGULATION OF OPIOID PEPTIDE SYNTHESIS AND PROCESSING IN ADRENAL CHROMAFFIN CELLS BY CATECHOLAMINES AND CYCLIC ADENOSINE $3^{\prime}: 5^{\prime}$-MONOPHOSPHATE ${ }^{1}$
}

\author{
STEVEN P. WILSON, ${ }^{*, 2}$ CHRISTOPHER D. UNSWORTH, $\ddagger$ AND O. HUMBERTO VIVEROS $\ddagger$ \\ * Department of Pharmacology, Duke University Medical Center, Durham, North Carolina 27710 and $\ddagger$ Department of Medicinal \\ Biochemistry, Wellcome Research Laboratories, Research Triangle Park, North Carolina 27709
}

Received January 23, 1984; Revised April 9, 1984; Accepted May 16, 1984

\begin{abstract}
Primary cultures of bovine adrenal medullary chromaffin cells were used to study the regulation of opioid peptide (OP) synthesis. Chromaffin cells continously exposed to tetrabenazine, a drug that depletes cellular catecholamine stores, increase their OP contents between $32 \mathrm{hr}$ and 6 days of treatment. At no time following tetrabenazine addition were increases in opiate receptor-inactive enkephalin-containing peptides (IECPs) observed. Because IECPs may serve as precursors to OPs, these results suggest increased processing of OP precursors following treatment with catecholamine-depleting drugs in addition to an increased rate of OP precursor synthesis. The increases in cellular OP levels induced by tetrabenazine were approximately proportional to the depletion in cellular catecholamines produced by this drug. Also, the effects of tetrabenazine on chromaffin cell OP and IECP contents were mimicked by inhibitors of catecholamine biosynthesis and other agents that decreased catecholamine stores, but not by supplementing the culture medium with catecholamines or catecholamine receptor agonists. Addition of 8-bromo-cAMP or forskolin, an activator of adenylate cyclase, to chromaffin cell cultures increased both OP and IECP stores. Inhibitors of cyclic nucleotide phosphodiesterase also increase chromaffin cell OP and IECP contents, although it is unclear whether these increases result from increased cyclic nucleotide levels. Hence, both alterations in some intracellular catecholamine pool and elevations of cAMP levels may trigger increases in the synthesis and processing of OPs and IECPs in the adrenal medullary chromaffin cell.
\end{abstract}

Adrenal medullary chromaffin cells contain high concentrations of opioid peptides (OPs) including Met- and Leu-enkephalin (Schultzberg et al., 1978; Lewis et al., 1979; Viveros et al., 1979; Yang et al., 1980) as well as larger enkephalin-containing peptides that are inactive in enkephalin radioreceptor assays (IECPs; Lewis et al., 1979). Both OPs and IECPs are derived from a 30,000-dalton proenkephalin molecule (for review, see Udenfriend and Kilpatrick, 1983) and are stored with catecholamines in chromaffin vesicles (Viveros et al., 1979; Varndell et al., 1982). Treatment with reserpine in vivo produces depletion of adrenal medullary catecholamines, without an initial decrease in OP levels, followed by a delayed elevation of OP levels, suggesting that there is regulation of adrenal medullary

\footnotetext{
${ }^{1}$ We wish to thank John T. Rowland and Dorothy L. Kamin for technical assistance. Catecholamine analyses on chromaffin cells treated with brocresine and 1-cyclohexyl-2-mercaptoimidazole were performed by Frank S. Menniti. We also wish to thank Dr. Emmanuel J. Diliberto, Jr., and Dr. Norman Kirshner for helpful discussions and for comments on the manuscript. Portions of this work were supported by a Grant-in-Aid (to S. P. W.) from the American Heart Association and contributed in part by the North Carolina Affiliate and by grants (to S. P. W.) from the North Carolina United Way, the North Carolina Affiliate of the American Heart Association, and Burroughs Wellcome Co.

${ }^{2}$ To whom correspondence should be addressed.
}

OP content (Viveros et al., 1980). Adrenal medullary OP stores depleted via neurogenic stimulation return to normal or abovenormal levels within a few days, also suggesting regulation of these peptide stores (Viveros et al., 1980).

Primary cultures of bovine chromaffin cells are useful for studying the synthesis, storage, and secretion of OPs and IECPs in the adrenal medulla because of the high OP content of the bovine gland (Viveros et al., 1979) and the retention of many of the in vivo properties of the cells for at least 2 weeks in culture (Waymire et al., 1977, 1983; Kilpatrick et al., 1980; Wilson et al., 1980, 1981a, 1982; Rossier et al., 1981; Wilson and Viveros, 1981; Livett et al., 1983; Wilson and Kirshner, $1983 \mathrm{~b})$. Treatment of cultured chromaffin cells with reserpine depletes cellular catecholamines and produces a doubling of $\mathrm{OP}$ levels within 2 to 3 days which results, at least in part, from increased de novo synthesis of enkephalins (Wilson et al., 1980, 1981a). These newly synthesized OPs are stored in functional chromaffin vesicles as evidenced by their subcellular distribution (Wilson et al., 1981b) and by the strict proportionality of OP and catecholamine secretion upon stimulation with nicotine from both control and reserpine-treated cells (Wilson et al., 1982). Tetrabenazine, another inhibitor of catecholamine uptake into chromaffin vesicles, also produces catecholamine depletion and an elevation in OP content (Wilson et al., 1982). The dual effects of these drugs in depletion of cellular catecholamine contents and in increasing OP levels led to the suggestion that an intracellular catecholamine pool or extra- 
cellular catecholamine levels may regulate OP biosynthesis in chromaffin cells (Wilson et al., 1981a).

The present studies were undertaken to elucidate the mechanism(s) whereby treatment with agents that deplete chromaffin cell catecholamines leads to an elevation in cellular OP content. We describe attempts to correlate intracellular and extracellular catecholamine levels with effects on cellular $\mathrm{OP}$ and IECP contents and present evidence that cyclic adenosine $3^{\prime}: 5^{\prime}$-monophosphate (cAMP) may also be important in the regulation of chromaffin cell OP levels. Preliminary reports of portions of this work have appeared (Wilson et al., 1981b, c).

\section{Materials and Methods}

Materials. Reserpine phosphate was generously provided by Ciba Pharmaceutical Co. Brocresine was a gift from Lederle Laboratories. The dopamine $\beta$-hydroxylase inhibitor 1-cyclohexyl-2-mercaptoimidazole was kindly provided by Eli Lilly and Co. Tetrabenazine was obtained from Hoffmann-LaRoche Inc. Tranylcypromine sulfate was obtained from Smith. Kline and French Laboratories. Forskolin was obtained from Calbiochem-Behring Corp. L-1-Tosylamide-2-phenylethyl chloromethyl ketone (TPCK)-treated trypsin was obtained from Millipore Corp. Carboxypeptidase B, pargyline hydrochloride, iproniazid phosphate, $\alpha$-methyl-p-tryosine, apomorphine hydrochloride, cyclic nucleotide phosphodiesterase inhibitors, and cyclic nucleotide analogues were obtained from Sigma Chemical Co. The 2 -aminotetralins were synthesized and provided by Dr. J. McDermed, Burroughs Wellcome Co. (McDermed et al., 1975).

Cell culture. Chromaffin cells were isolated from bovine adrenal medullae by digestion with collagenase followed by density gradient centrifugation on Percoll (Wilson and Viveros, 1981; Wilson and Kirshner, $1983 \mathrm{c}$ ). The cells were routinely plated at a density of 0.4 to 0.5 $\times 10^{6} / 2-\mathrm{cm}^{2}$ well in serum-containing medium and were maintained in serum-free medium $(500 \mu \mathrm{l} /$ well) beginning 1 or 2 days after plating (Wilson and Viveros, 1981; Wilson and Kirshner, 1983c).

Experiments were initiated after the cells had been in serum-free medium for 1 to 4 days. Drugs were added direstly to the cultures as 50 - to 100 -fold concentrated solutions. Forskolin was dissolved in $95 \%$ ethanol and added to cultures such that the final ethanol concentration was $0.1 \%$ or less. Ethanol at this concentration did not alter chromaffin cell OP, IECP, or catecholamine contents. For analysis of cellular catecholamine, OP, and IECP levels, the medium was removed from the cultures and the cells were extracted with $1.0 \mathrm{M}$ acetic acid. In some experiments, the cell monolayer was washed with a cold balanced salts solution before acid extraction, a treatment that did not alter the measured catecholamine, OP, or IECP content.s. Catecholamines in the culture medium were determined following acidification of aliquots of the medium to a final concentration of $0.1 \mathrm{M}$ acetic acid. For protein determinations, cultures were washed once with a cold balanced salts solution and cellular protein was precipitated on the culture dish with $0.4 \mathrm{M}$ perchloric acid (Wilson and Kirshner, 1983a).

Determination of OPs and IECPs. Opiate activity, given as equivalents of Leu- or Met-enkephalin, was measured by displacement of $\left.{ }^{125} \mathrm{I}\right]-\mathrm{D}-\mathrm{Ala}^{2}, \mathrm{D}-\mathrm{Leu}^{5}$-enkephalin from rat, porcine, or bovine brain membrane receptors (Chang and Cuatrecasas, 1979; Wilson et al., 1981a). The three membrane preparations contain opiate receptors with very similar ligand specificity. Opiate activity detected in chromaffin cell extracts is pronase sensitive and gives displacement curves in the radioreceptor assay parallel to OP standards (Viveros et al., 1979, 1980; Wilson et al., 1981d; S. P. Wilson, unpublished results). This opiate activity derives from peptides of $M_{\mathrm{r}}<5000$ including Metand Leu-enkephalin (Viveros et al., 1979; Wilson et al., 1980, 1982; see also Lewis et al., 1979; Rossier et al., 1981). The levels of Met- and Leu-enkephalin, determined following high performance liquid chromatography, increase in reserpine-treated chromaffin cells to an extent similar to that for total opiate activity (Wilson et al., 1980), further substantiating the validity of the radioreceptor assay. Total opiate activity was measured after sequential digestion of neutralized cell extracts with trypsin $(2.2 \mu \mathrm{g} / \mathrm{ml})$ and carboxypeptidase B $(1 \mu \mathrm{g} / \mathrm{ml})$ by the method of Wilson et al. (1982). Opiate activity in IECPs is reported as the difference between opiate activity measured following the enzyme treatments and that measured without enzymatic digestion.

Catecholamine assays. The total catecholamine content of cell cultures was determined fluorometrically by the method of Anton and Sayre (1962) using epinephrine as the standard. Norepinephrine, epi- nephrine, and dopamine levels were determined by high performance liquid chromatography with electrochemical detection (Bioanalytical Systems LC-153). The extracts were chromatographed on a C-18 reverse phase column (Alltech) eluted isocratically with a solution of $93 \%$ $0.15 \mathrm{M}$ monochloroacetic acid, $1 \mathrm{~mm}$ EDTA, and $15 \mathrm{mg} / \mathrm{liter}$ of sodium octyl sulfate, $\mathrm{pH} 3.0$, and $7 \%$ methanol. The electrochemical detector used a TL-5A or TL-8A glassy carbon electrode set at $0.85 \mathrm{~V}$.

Other methods. Acid-precipitated protein was dissolved in sodium hydroxide and estimated by the method of Lowry et al. (1951). Dopamine $\beta$-hydroxylase activity was measured by the method of Nagatsu and Udenfriend (1972) as previously modified (Wilson and Kirshner, 1983a). Data are presented as the mean \pm SEM of determinations on the indicated number of cultures, usually from single experiments. In all cases at least one additional experiment on a separate cell preparation confirmed the results presented.

\section{Results}

\section{Catecholamines}

Tetrabenazine and reserpine. Because the primary actions of tetrabenazine and reserpine are to deplete cellular catecholamine stores by inhibiting chromaffin vesicle catecholamine uptake, we explored in detail the relationship between cellular and extracellular amine levels and the elevation in OPs produced by these drugs. Addition of 0.3 to $100 \mu \mathrm{M}$ tetrabenazine to chromaffin cell cultures produced depletion of cellular catecholamines and an increase in OP levels within 3 days (Fig. 1). At concentrations of 200 and $300 \mu \mathrm{M}$ tetrabenazine, OP levels attained are lower than those observed with $100 \mu \mathrm{M}$ tetrabenazine, although no change in the protein content of the cultures was observed at any concentration of the drug tested (not shown). Each concentration of tetrabenazine tested which increased chromaffin cell OP levels concomitantly depleted cellular catecholamines; indeed, the increases in OP levels induced by tetrabenazine concentrations between 0.3 and $100 \mu \mathrm{M}$ are approximately proportional to the catecholamine depletion observed at these drug concentrations.

The time course of the effects of tetrabenazine on the catecholamine, $\mathrm{OP}$, and IECP contents of chromaffin cell cultures was also examined (Fig. 2). Tetrabenazine induced exponential losses of each catecholamine in the cells with approximate halftimes for loss of $2.5,17$, and $20 \mathrm{hr}$ for dopamine, norepinephrine, and epinephrine, respectively. Of the dopamine lost from the cells as a result of tetrabenazine treatment, only a small amount appeared in the medium (not shown); $4 \mathrm{hr}$ after tetrabenazine addition, dopamine levels in the medium had increased from less than $0.01 \mathrm{nmol} /$ culture to $0.17 \pm 0.01(n=$ 3) $\mathrm{nmol} /$ culture, an amount equal to only $13 \%$ of the dopamine lost from the cells during the same time period. Dopamine added to the medium of chromaffin cell cultures was lost from the medium with an apparent half-life of 9 to $10 \mathrm{hr}$, with only a small fraction of the added amine accumulated by the cells, making it unlikely that the medium dopamine levels were grossly underestimated because of degradation. The rapid rate of dopamine loss probably resulted from the inhibition of tyrosine hydroxylase by elevated cytoplasmic catecholamine levels and the conversion of dopamine to norepinephrine in addition to loss from the cell. Norepinephrine and epinephrine reached high concentrations in the medium of tetrabenazinetreated chromaffin cell cultures, being elevated 40 - and 20 -fold, respectively, over those of untreated cultures after $24 \mathrm{hr}$ (Fig. $2 B)$. The amounts of epinephrine in the medium of tetrabenazine-treated cultures accounted for less than one-half of that lost from the cells, suggesting that this amine may be more susceptible to oxidation than norepinephrine, once outside of the cell.

In contrast to the apparent first-order kinetics of tetrabenazine-induced catecholamine loss from the cells, the loss of catecholamines from the total culture (medium + cells) appeared to be zero-order with approximately $12 \mathrm{nmol}$ of cate- 


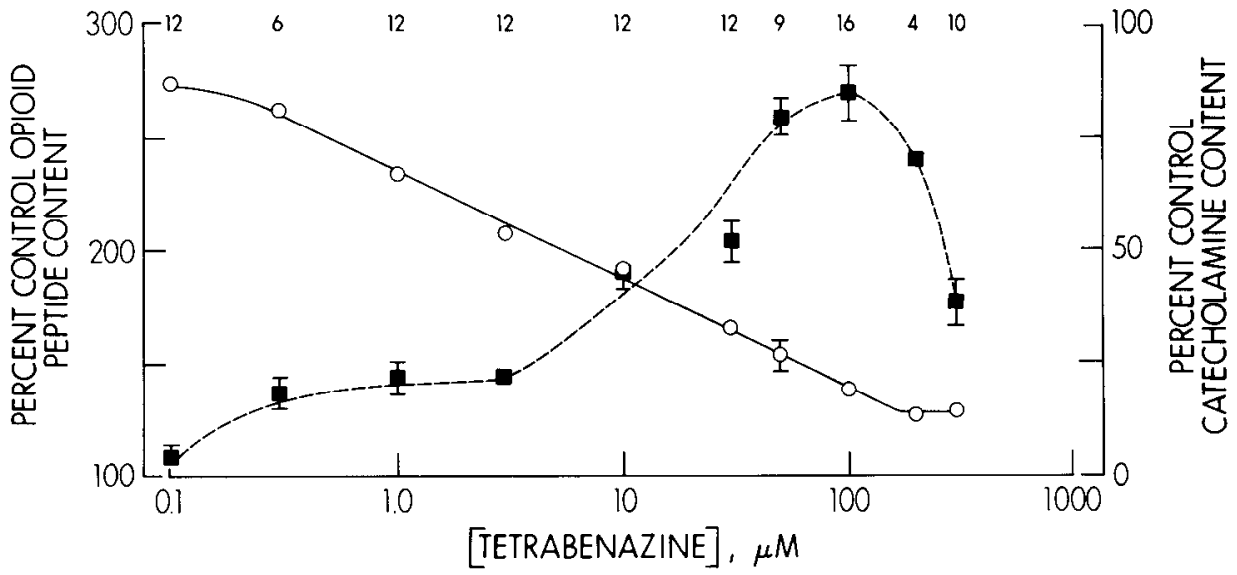

Figure 1. Effects of various concentrations of tetrabenazine on chromaffin cell catecholamine and OP contents. Chromaffin cells were cultured in the presence of the indicated concentrations of drug for 3 days. The data shown are the mean \pm SEM determined on the number of individual cultures shown at the top of the figure and represent experiments with five separate cell preparations. Error bars are shown only when larger than the symbol used. $O$, total cellular catecholamines; $\mathbf{D}$, cellular opioid peptides.
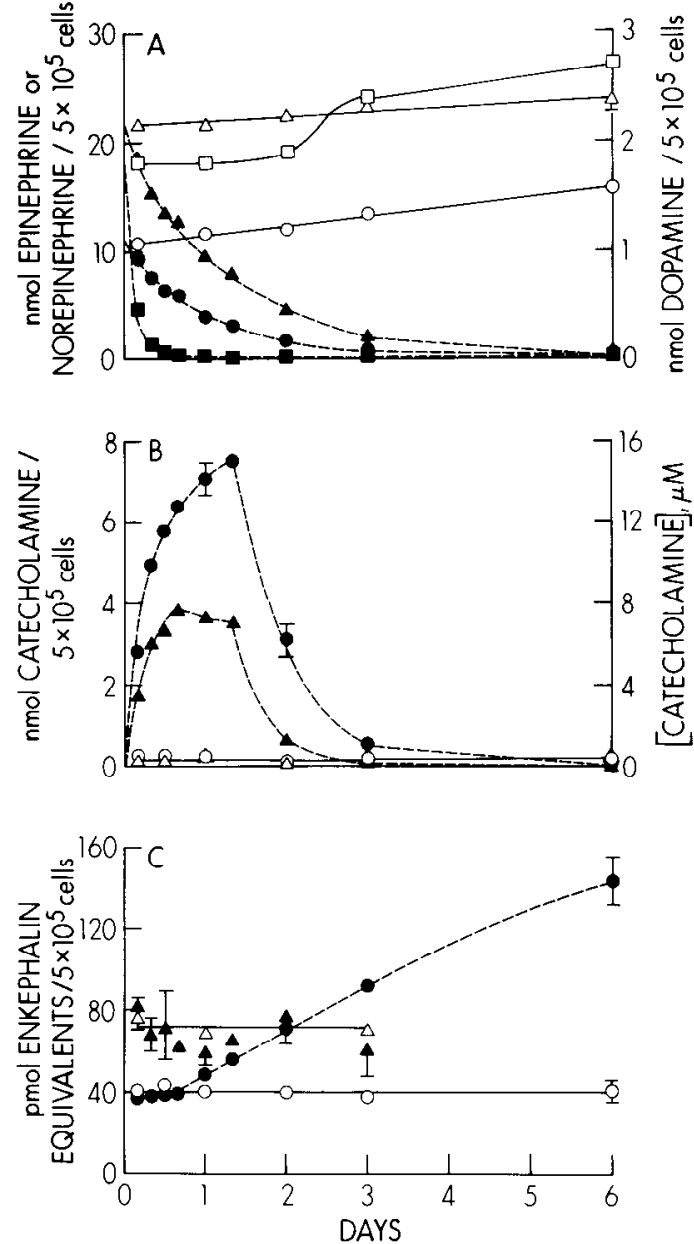

Figure 2. Intracellular catecholamine, extracellular catecholamine $\mathrm{OP}$, and IECP levels in untreated chromaffin cells and in cells treated with tetrabenazine. Triplicate cultures were analyzed for each data point; error bars are shown only when larger than the symbol used. Data from cultures treated with tetrabenazine ( $100 \mu \mathrm{M}$ present throughout) are shown with solid symbols; data from untreated cultures are shown with open symbols. A, Cellular norepinephrine $(\mathrm{O}, \bullet)$, epinephrine $(\Delta, \boldsymbol{\Delta})$, and dopamine $(\square, \boldsymbol{\square}) . B$, Norepinephrine $(O, \bullet)$ and epinephrine $(\triangle, \Delta)$ levels in the culture medium. $C$, Cellular OP $(O, \bullet)$ and IECP $(\Delta, \Delta)$ levels. These cells were cultured in the presence of 0.2 unit of insulin $/ \mathrm{ml}$, a treatment that increases OP and IECP levels (a new stable level of these peptides was obtained before this experiment was begun) and catecholamines. Similar experiments performed on cells cultured without insulin produced similar results. cholamine lost per day. Zero-order kinetics were also observed for the loss of norepinephrine from culture medium incubated in the absence of cells at $37^{\circ} \mathrm{C}$, suggesting that the loss from tetrabenazine-treated cultures represented nonenzymatic catecholamine oxidation. No detectable levels of the catecholamine metabolites normetanephrine, metanephrine, 3-methoxy-4-hydroxymandelic acid, 3,4-dihydroxphenylglycol, or 3,4-dihydroxymandelic acid were found in the culture medium or cell extracts of untreated or tetrabenazine-treated cultures.

Tetrabenazine-treated chromaffin cells exhibited significantly $(p<0.01)$ elevated OP levels by $32 \mathrm{hr}$ after addition of the drug. The increase in chromaffin cell OP levels proceeded almost linearly between 1 and 6 days of treatment, reaching $350 \%$ of control at 6 days. Other experiments of longer duration show that no further increase in cell OP levels occurred after 6 to 7 days. Chromaffin cells (sister cultures to those used for the experiment shown in Fig. 2) treated with reserpine exhibited increased OP levels parallel to those of tetrabenazine-treated cells for the first 2 days of treatment but reached only $77 \pm 5$ and $90 \pm 5 \mathrm{pmol}$ of OP/culture at days 3 and 6 , respectively, despite similar catecholamine depletion from the cells and accumulation in the medium. In contrast to the increased $O P$ levels resulting from tetrabenazine treatment, chromaffin cell IECP levels remained constant for the first 3 days (Fig. $2 C$ ). A similar effect was noted with reserpine (not shown). Although IECP levels were not determined beyond 3 days of tetrabenazine treatment in the experiment shown in Figure 2, in other experiments (not shown), total opiate activity, OPs + IECPs, in the drug-treated cultures increased either slowly or not at all between 3 and 6 days; IECP levels occasionally decreased during this period.

We exploited the reversibility of tetrabenazine (Tomlinson, 1977 ) to determine whether the continued presence of this drug was required to obtain increases in chromaffin cell OPs (Table I). Removal of tetrabenazine from the cultures at different times severely reduced or halted further cellular catecholamine depletion. The increase in OP levels 4 days after addition of tetrabenazine was approximately proportional to the extent of catecholamine depletion (correlation coefficient $=0.97 ; p<$ 0.001 ). These results, together with those in Figures 1 and 2, suggested that the effects of tetrabenazine or reserpine may be mediated through changes in extracellular catecholamine levels or changes in intracellular catecholamine pools.

Adrenergic receptor agonists and antagonists. Single additions to the medium of epinephrine, norepinephrine, or dopamine (1 to $100 \mu \mathrm{M}$ final concentration) or 3,4-dihydroxyphenylalanine $(10 \mu \mathrm{M})$ failed to elevate chromaffin cell OP levels or to alter total catecholamine stores within 2 to 3 days. Single or repetitive (8-hr intervals over the first $24 \mathrm{hr}$ ) addition of norepinephrine and epinephrine, to give concentrations similar to those 
TABLE I

Depletion of catecholamine and elevation of $O P$ levels in chromaffin cells exposed to tetrabenazine

Chromaffin cell cultures were exposed to $50 \mu \mathrm{M}$ tetrabenazine, and the drug was removed by replacing the culture medium three times at 10-min intervals at the times indicated. The cultures were harvested immediately or were harvested $96 \mathrm{hr}$ after tetrabenazine addition. All culture media contained $1 \mathrm{mg}$ of BSA $/ \mathrm{ml}$. Data obtained from triplicate cultures are expressed as the percentage of that from cultures without tetrabenazine but washed identically. Untreated, washed cultures $(5 \times$ $10^{5}$ cells) contained $9.2 \pm 0.2 \mathrm{pmol}$ of $\mathrm{OP}(n=9)$ and $25.0 \pm 0.3 \mathrm{nmol}$ of catecholamine ( $n=18$ ); untreated, unwashed cultures ( $96 \mathrm{hr}$ ) contained $9.2 \pm 0.1 \mathrm{pmol}$ of $\mathrm{OP}(n=3)$ and $27.3 \pm 0.3 \mathrm{nmol}$ of catecholamine $(n=3)$. Levels of OPs were significantly $(p<0.005)$ elevated by tetrabenazine at each time examined.

\begin{tabular}{|c|c|c|c|}
\hline \multirow{2}{*}{$\begin{array}{l}\text { Time of } \\
\text { Washout }\end{array}$} & \multicolumn{2}{|c|}{ Catecholamines } & \multirow{2}{*}{$\begin{array}{l}\text { Opioid Peptides } \\
\text { at } 96 \mathrm{hr}\end{array}$} \\
\hline & At Washout & At $96 \mathrm{hr}$ & \\
\hline hours & \multicolumn{2}{|c|}{$\%$} & $\%$ \\
\hline 16 & $70.4 \pm 0.8$ & $61.6 \pm 2.0^{\alpha}$ & $124 \pm 2$ \\
\hline 24 & $59.2 \pm 2.0$ & $57.6 \pm 1.6$ & $148 \pm 8$ \\
\hline 32 & $54.4 \pm 0.8$ & $50.4 \pm 1.2$ & $145 \pm 2$ \\
\hline 96 & & $13.9 \pm 0.4$ & $197 \pm 7$ \\
\hline
\end{tabular}

${ }^{a} p<0.02$ compared to catecholamine content immediately after washout.

achieved in the medium of tetrabenazine-treated cells (15 and $7.5 \mu \mathrm{M}$, respectively; Fig. $2 B$ ), failed to modify chromaffin cell OP levels by 3 days. Likewise, the adrenergic receptor agonists phenylephrine (final concentration of $10 \mu \mathrm{M}$ ) and isoproterenol ( $1 \mathrm{nM}$ to $10 \mu \mathrm{M}$ ) failed to enhance chromaffin cell OP stores. The effect of reserpine on cell OP levels was not blocked by phentolamine $(1 \mu \mathrm{M})$, propranolol $(10 \mu \mathrm{M})$, or haloperidol $(10$ to $100 \mu \mathrm{M}$ ). Two days after addition of $100 \mu \mathrm{M}$ haloperidol to chromaffin cell cultures, catecholamines were depleted by $65 \%$, in accord with the ability of haloperidol to inhibit catecholamine uptake into chromaffin vesicles (Pletscher, 1977), and OP levels were increased by $40 \%$. These results suggest that extracellular catecholamines and cell surface catecholamine receptors do not mediate the effects of tetrabenazine or reserpine on chromaffin cell OP levels.

Inhibitors of catecholamine degradation and synthesis. We reasoned that, if depletion of intracellular catecholamine pools were important in regulation of chromaffin cell OP levels, monoamine oxidase (MAO) inhibitors might antagonize the reserpine- or tetrabenazine-induced increases in OPs. However, one such inhibitor, tranylcypromine, enhanced cellular OP levels alone, without increasing IECP contents (Table II). At the same time, tranylcypromine reduced chromaffin cell dopamine levels transiently and produced small decreases in the norepinephrine and epinephrine contents of the cells. In 14 separate experiments in which chromaffin cells were exposed to 10 to $25 \mu \mathrm{M}$ tranylcypromine for 3 days, cellular OP levels were increased to $131 \pm 3 \%$ of those in untreated cells, whereas similar concentrations of pargyline (7 experiments) or iproniazid ( 6 experiments) produced OP levels $112 \pm 15 \%$ and $104 \pm$ $13 \%$ of control, respectively. Nialamide also failed to increase cellular OP levels. Pargyline, iproniazid, and nialamide either produced no catecholamine depletion or produced smaller decreases in cellular catecholamine contents than did tranylcypromine at equal concentrations. Although tranylcypromine often produced a partial, but significant antagonism of reserpine- or tetrabenazine-induced depletion of total cellular catecholamines, this MAO inhibitor failed to block the increase in cellular OP levels induced by reserpine or tetrabenazine and, in fact, often enhanced the increase in OPs produced by these drugs.

Various inhibitors of catecholamine biosynthesis were tested in an attempt to determine whether alternate means of catecholamine depletion could mimic the effects of reserpine and tetrabenazine on chromaffin cell OP levels (Table III). $\alpha$ Methyl- $p$-tyrosine, an inhibitor of tyrosine hydroxylase, reduced chromaffin cell dopamine levels to less than $10 \%$ of control within $24 \mathrm{hr}$ (not shown) and produced a gradual decline in norepinephrine and cpinephrinc stores. Averaging the results of four separate experiments showed that the rates of norepinephrine and epinephrine loss over the first 3 days of treatment with $\alpha$-methyl-p-tyrosine appeared to be first-order, with apparent half-times of 4.3 and 9.9 days, respectively. These values are similar to the half-times for the turnover of $\left[{ }^{3} \mathrm{H}\right]$ norepinephrine ( 4 to 5 days) and $\left[{ }^{3} \mathrm{H}\right]$ epinephrine (9 to 17 days) in untreated chromaffin cell cultures (Corcoran et al., 1984). These data suggest a complete blockade of tyrosine hydroxylase by $1 \mathrm{mM} \alpha$-methyl- $p$-tyrosine. Levels of OPs but not IECPs in chromaffin cells treated with $\alpha$-methyl-p-tyrosine were increased after 3 and 6 days' exposure to the drug.

An inhibitor of dopa decarboxylase, brocresine, and an inhibitor of dopamine $\beta$-hydroxylase, 1-cyclohexyl-2-mercaptoimidazole (CHMI), also produced an expected gradual decline in epinephrine and norepinephrine stores (Table III). Brocresine rapidly reduced cellular dopamine levels and produced increases in OP contents without alterations in IECP levels as found for chromaffin cells treated with reserpine, tetrabenazine, or $\alpha$ methyl-p-tyrosine. Chromaffin cells treated with CHMI increased their dopamine contents, as would be expected for an inhibitor of dopamine $\beta$-hydroxylase, and produced a significant increase in OP levels, but smaller than that seen with brocresine, without changing IECP stores. Although the dopamine accumulated by CHMI-treated cells did not compensate for the loss of epinephrine and norepinephrine, total catecholamine depletion was less in cells treated with CHMI than in brocresine-treated cells, possibly accounting for the smaller

TABLE II

Effect of tranylcypromine on chromaffin cell catecholamines, OPs, and IECPs Quadruplicate cultures with or without $20 \mu \mathrm{M}$ tranylcypromine added at 0 days were harvested at the times indicated.

\begin{tabular}{|c|c|c|c|c|c|c|}
\hline Addition to Medium & Days & $\mathrm{NE}^{a}$ & $\mathrm{E}$ & $\mathrm{DA}$ & $\mathrm{OP}$ & IECP \\
\hline & & \multicolumn{3}{|c|}{$\mathrm{nmol} / 5 \times 10^{5}$ cells } & \multicolumn{2}{|c|}{ pmol/ $5 \times 10^{5}$ cells } \\
\hline None & $\begin{array}{l}1 \\
3 \\
5\end{array}$ & $\begin{array}{l}13.1 \pm 0.1 \\
12.7 \pm 0.1 \\
12.0 \pm 0.2\end{array}$ & $\begin{array}{l}29.3 \pm 0.3 \\
29.7 \pm 0.3 \\
28.8 \pm 1.2\end{array}$ & $\begin{array}{l}0.36 \pm 0.01 \\
0.33 \pm 0.01 \\
0.25 \pm 0.01\end{array}$ & $\begin{array}{l}23.0 \pm 0.5 \\
21.7 \pm 0.7 \\
18.1 \pm 0.7\end{array}$ & $\begin{array}{l}36.0 \pm 1.5 \\
37.3 \pm 3.8 \\
44.5 \pm 3.0\end{array}$ \\
\hline Tranylcypromine & $\begin{array}{l}1 \\
3 \\
5\end{array}$ & $\begin{array}{l}11.0 \pm 0.2^{b} \\
11.1 \pm 0.1^{b} \\
10.2 \pm 0.2^{b}\end{array}$ & $\begin{array}{l}25.7 \pm 0.6^{c} \\
28.1 \pm 0.3^{c} \\
25.4 \pm 0.4^{d}\end{array}$ & $\begin{array}{l}0.23 \pm 0.005^{b} \\
0.28 \pm 0.01^{d} \\
0.31 \pm 0.01^{c}\end{array}$ & $\begin{array}{l}27.5 \pm 0.7^{c} \\
28.0 \pm 1.0^{c} \\
28.3 \pm 0.3^{b}\end{array}$ & $\begin{array}{l}34.8 \pm 1.4 \\
34.8 \pm 1.8 \\
36.3 \pm 2.3\end{array}$ \\
\hline
\end{tabular}

${ }^{a} \mathrm{NE}$, norepinephrine; E, epinephrine; DA, dopamine.

${ }^{b} p<0.001$ compared to no additions.

' $p<0.01$ compared to no additions.

${ }^{d} p<0.05$ compared to no additions. 
TABLE III

Effects of inhibitors of catecholamine biosynthesis on chromaffin cell catecholamine, $O P$, and IECP stores

For experiment 1 , chromaffin cells $\left(5 \times 10^{5}\right.$ per well) were treated with $1 \mathrm{mM} \alpha$-methyl-p-tryosine at 0 days. Quadruplicate cultures were harvested at the times indicated and analyzed for catecholamine levels and opiate activity. For experiment 2, quadruplicate cultures of chromaffin cells $\left(5 \times 10^{5}\right.$ per well) were treated with $10 \mu \mathrm{M} 7$-HDPT at 0 days. In experiment 3 , chromaffin cells $\left(10^{6}\right.$ per 35 -mm dish) were treated with 150 $\mu \mathrm{M}$ brocresine or $150 \mu \mathrm{M}$ CHMI. Triplicate cultures were harvested and analyzed after 3 days. No further increases in OPs, decreases in catecholamines, or alterations in IECPs relative to untreated cultures were observed with up to 6 days of treatment with these drugs.

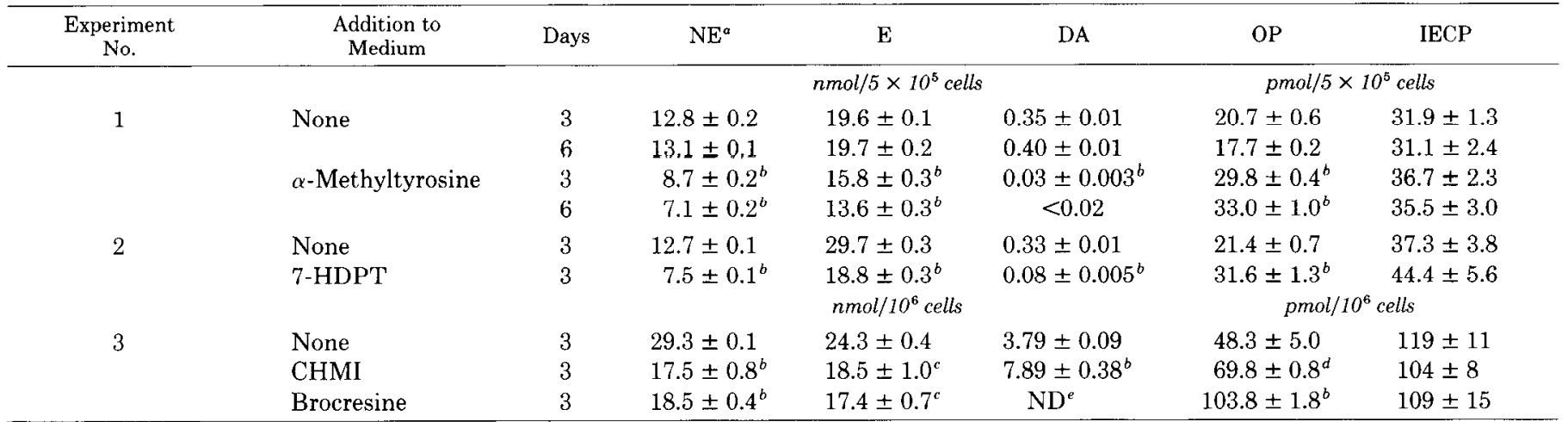

${ }^{a}$ NE, norepinephrine; E, epinephrine; DA, dopamine.

${ }^{b} p<0.001$ compared to no addition.

${ }^{c} p<0.01$ compared to no addition.

${ }^{d} p<0.02$ compared to no addition.

e ND, not detectable.

increase in OPs in cells treated with the dopamine $\beta$-hydroxylase inhibitor.

Other agents. Several other agents were tested for their ability to enhance OP levels in cultured chromaffin cells. The dopamine receptor agonist 7 -hydroxy- $N, N$-di- $n$-propyl-2-aminotetralin (7-HDPT) elevated chromaffin cell OP levels (Table III). The catecholamine levels of cells treated with 7-HDPT declined at least as fast as those in cells treated with $\alpha$-methyl-ptyrosine, except that dopamine levels were reduced to 20 to $30 \%$ of control rather than the lower value observed with the tyrosine hydroxylase inhibitor. No increases in the IECP stores of chromaffin cells treated with 7-HDPT were observed. Treatment of chromaffin cells with 6,7-dihydroxy-2-aminotetralin (ADTN), also a dopamine receptor agonist, produced a similar pattern of catecholamine depletion, although this drug appeared to be less potent than 7-HDP'T (not shown). ADTN was also less potent than 7-HDPT in increasing OP levels. These drugs, 7-HDPT and ADTN, may act as tyrosine hydroxylase inhibitors (Waggoner et al., 1980) or may produce catecholamine depletion via other mechanisms, such as inhibition of vesicular amine uptake which would produce a similar pattern of catecholamine depletion (see Fig. 2). A third dopamine receptor agonist, apomorphine, increased chromaffin cell dopamine levels 1- to 3 -fold by 3 days of treatment with reductions of up to $30 \%$ in norepinephrine and epinephrine levels by 3 to 6 days (not shown). Increases in OP levels were not consistently observed and, when found, were apparent only after 4 to 6 days. The effects of apomorphine were similar to those of CHMI, suggesting that this compound may inhibit dopamine $\beta$-hydroxylase. Apomorphine did inhibit dopamine $\beta$-hydroxylase activity in adrenal medullary homogenates: a concentration of approximately $300 \mu \mathrm{M}$ produced $50 \%$ inhibition (not shown). Hence, the actions of dopamine receptor agonists on chromaffin cell catecholamine and OP contents appear distinct from their stimulatory effects on cell surface dopamine receptors.

A number of other compounds were found to have no effect on chromaffin cell OP levels (single additions with cells analyzed after 2 to 3 days of treatment), including: [D-Ala ${ }^{2}, \mathrm{D}-\mathrm{Leu}^{5}$ ] enkephalin $(1 \mu \mathrm{M}), 5$-hydroxytryptamine $(10 \mu \mathrm{M})$, octopamine $(10 \mu \mathrm{M}), N$-methyl dopamine $(10 \mu \mathrm{M})$, desmethylimipramine $(1 \mu \mathrm{M})$, and NGF $(100 \mathrm{ng} / \mathrm{ml})$.

\section{$c A M P$}

Because cultured chromaffin cells treated with reserpine exhibit increased levels of tryosine hydroxylase (Wilson et al., 1981a), and since treatment of chromaffin cells with analogues of cAMP or activators of adenylate cyclase also increase tyrosine hydroxylase levels (Waymire et al., 1977; Kumakura et al., 1979), we examined the possibility that cAMP may regulate $\mathrm{OP}$ synthesis in chromaffin cells. In initial experiments the addition of 8-bromo-cAMP to chromaffin cells, which were examined only for OP content, did not consistently elevate OP levels. However, in further, more detailed experiments, addition of 8-bromo-cAMP or forskolin, an activator of adenylate cyclase activity in a variety of cell types (Seamon et al., 1981), produced elevations in chromaffin cell IECP levels and usually elevated OP levels as well (Table IV). Total opiate activity (OPs + IECPs) was elevated to a similar extent by tetrabenazine (129 $\pm 3 \%$ of control), 8-bromo-cAMP (128 $\pm 5 \%$ of control), and $10 \mu \mathrm{M}$ forskolin (129 $\pm 3 \%$ of control). Catecholamine levels were also affected by 8-bromo-cAMP and forskolin treatments (Table IV): dopamine levels were increased but epinephrine levels decreased. No consistent change in chromaffin cell norepinephrine levels treated with these compounds was observed (Table IV, see Figs. 3 and 4). Chromaffin cell cultures treated with 8-bromo-cAMP or forskolin also increased in protein content. The effects of dibutyryl cAMP were similar to those of 8-bromo-cAMP and forskolin (not shown).

Phosphodiesterase inhibitors. Theophylline and 3-isobutyl, 1methylxanthine (IBMX), inhibitors of cyclic nucleotide phosphodiesterase, were also tested for their effects on chromaffin cell OP and IECP levels (Table V). Theophylline (2 to $5 \mathrm{mM}$ ) produced large increases in OP and IECP levels-larger increases than observed by any other treatment described thus far-and elevated dopamine and decreased epinephrine levels as seen with forskolin and 8-bromo-cAMP. Equal concentrations of theophylline and IBMX produced similar increases in the total opiate activity of the cultures, although theophylline altered catecholamine levels less than IBMX did.

Forskolin plus theophylline. In an attempt to dissociate the effects of forskolin and theophylline on cell protein and catecholamine contents from the effects of these compounds on OP 
TABLE IV

Effect of 8-bromo-cAMP and forskolin on chromaffin cell protein, catecholamine, $O P$, and IECP contents

Chromaffin cell cultures were maintained in the absence $(n=8)$ or the presence $(n=4)$ of the indicated drugs for 4 days and then analyzed for catecholamine, OP, and IECP levels. A duplicate set of cultures was analyzed for protein content.

\begin{tabular}{|c|c|c|c|c|c|c|}
\hline Addition to Medium & $\mathrm{OP}$ & IECP & $\mathrm{NE}^{a}$ & $\mathrm{E}$ & DA & Protein \\
\hline & \multicolumn{2}{|c|}{$\mathrm{pmol} / 5 \times 10^{5} \mathrm{cells}$} & \multicolumn{3}{|c|}{ nmol $/ 5 \times 10^{5}$ cells } & $\mu g / 5 \times 10^{5}$ cells \\
\hline None & $18.8 \pm 0.5$ & $48.2 \pm 1.2$ & $8.9 \pm 0.2$ & $27.5 \pm 0.3$ & $0.45 \pm 0.02$ & $61.5 \pm 0.6$ \\
\hline Tetrabenazine, $100 \mu \mathrm{M}$ & $36.9 \pm 0.5^{b}$ & $49.4 \pm 2.6$ & $0.5 \pm 0.04^{b}$ & $2.5 \pm 0.2^{b}$ & $<0.03$ & $66.3 \pm 1.4^{c}$ \\
\hline Forskolin, $10 \mu \mathrm{M}$ & $23.4 \pm 0.1^{b}$ & $62.8 \pm 1.8^{b}$ & $6.8 \pm 0.2^{b}$ & $12.9 \pm 0.2^{b}$ & $1.55 \pm 0.04^{b}$ & $84.2 \pm 1.0^{b}$ \\
\hline Forskolin, $50 \mu \mathrm{M}$ & $19.2 \pm 0.2$ & $62.6 \pm 3.6^{e}$ & $6.0 \pm 0.2^{b}$ & $8.8 \pm 0.6^{b}$ & $1.71 \pm 0.09^{b}$ & $88.6 \pm 3.5^{b}$ \\
\hline
\end{tabular}

${ }^{a} \mathrm{NE}$, norepinephrine; E, epinephrine; DA, dopamine.

${ }^{b} p<0.001$ compared to no additions.

${ }^{c} p<0.02$ compared to no additions.

${ }^{d} p<0.005$ compared to no additions.

${ }^{e} p<0.01$ compared to no additions.

TABLE V

Effects of phosphodiesterase inhibitors on chromaffin cell catecholamine, $O P$, and IECP levels

Cultures of chromaffin cells were maintained with the additions noted for 3 days; cultures were then harvested and analyzed for catecholamines, $O P$, and IECP contents.

\begin{tabular}{|c|c|c|c|c|c|c|}
\hline Addition to Medium & Number & $\mathrm{NE}^{a}$ & $\mathrm{E}$ & $\mathrm{DA}$ & OP & IECP \\
\hline & & \multicolumn{3}{|c|}{ nmol $/ 5 \times 10^{5}$ cells } & \multicolumn{2}{|c|}{$\mathrm{pmol} / 5 \times 10^{5}$ cells } \\
\hline None & 12 & $8.1 \pm 0.2$ & $25.3 \pm 0.5$ & $0.47 \pm 0.03$ & $14.1 \pm 0.4$ & $28.6 \pm 1.0$ \\
\hline Theophylline, $1 \mathrm{~mm}$ & 8 & $9.1 \pm 0.2^{b}$ & $24.6 \pm 0.4$ & $0.60+0.03^{c}$ & $21.3 \pm 0.4^{d}$ & $33.8 \pm 1.7^{e}$ \\
\hline Theophylline, $2 \mathrm{~mm}$ & 4 & $10.2 \pm 0.2^{d}$ & $23.4 \pm 0.3^{c}$ & $0.76 \pm 0.03^{d}$ & $25.3 \pm 1.5^{d}$ & $49.0 \pm 2.5^{d}$ \\
\hline Theophylline, $5 \mathrm{~mm}$ & 8 & $12.1 \pm 0.2^{d}$ & $16.9 \pm 0.3^{d}$ & $1.37 \pm 0.03^{d}$ & $34.7 \pm 1.3^{d}$ & $81.9 \pm 2.7^{d}$ \\
\hline $\mathrm{IBMX}, 1 \mathrm{mM}$ & 4 & $7.7 \pm 0.2$ & $19.3 \pm 0.3^{d}$ & $2.43 \pm 0.02^{d}$ & $18.9 \pm 0.2^{d}$ & $40.6 \pm 2.4^{d}$ \\
\hline
\end{tabular}

${ }^{a} \mathrm{NE}$, norepinephrine; E, epinephrine; DA, dopamine.

${ }^{b} p<0.005$ compared to no additions.

${ }^{c} p<0.01$ compared to no additions.

${ }^{d} p<0.001$ compared to no additions.

${ }^{e} p<0.02$ compared to no additions.

and IECP levels, we examined the concentration dependence of forskolin treatment and the time dependence of forskolin and theophylline treatment on chromaffin cells. Forskolin concentrations of $1 \mu \mathrm{M}$ and greater produced significant increases in the total opiate activity ( $118 \pm 3 \%$ of control, $p<0.02$ for 1 $\mu \mathrm{M}$ ) of chromaffin cell cultures after 3 days of treamtent (Fig. 3). Cellular dopamine levels were elevated by forskolin with a dose dependence similar to that of OP and IECP levels; epinephrine levels decreased only at concentrations of forskolin above $2 \mu \mathrm{M}$. In other experiments using forskolin concentrations up to $50 \mu \mathrm{M}$, no further increases in chromaffin cell OP and IECP levels were observed at concentrations greater than $5 \mu \mathrm{M}$, although dopamine levels increased and epinephrine levels decreased with increasing forskolin concentration. Addition of $1 \mathrm{~mm}$ theophylline to the cultures potentiated the effects of forskolin on chromaffin cell OP, IECP, and dopamine contents similarly, although theophylline addition produced only a small change in the apparent half-maximum forskolin

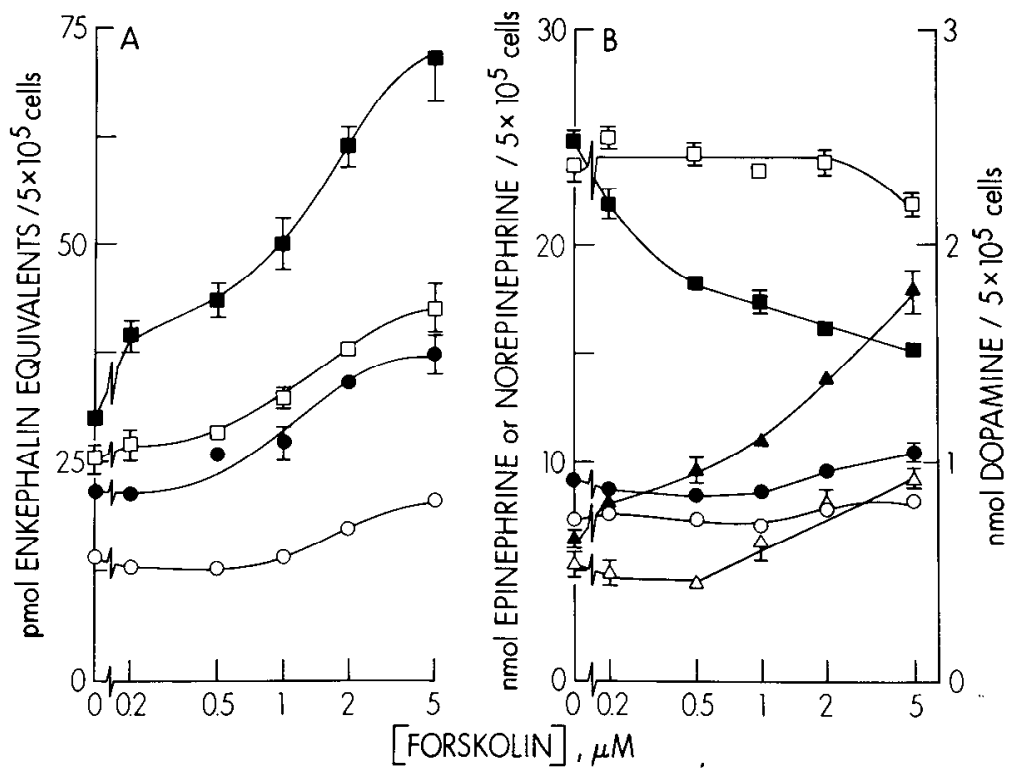

Figure 3. Effects of various concentrations of forskolin on chromaffin cell OP, IECP, and catecholamine stores. Chromaffin cells were cultured in the presence of the indicated concentrations of forskolin for 3 days with (solid symbols) or without (open symbols) theophylline $(1 \mathrm{mM})$. Quadruplicate cultures were harvested and analyzed for each data point; error bars are shown only when larger than the symbol used. $A, \mathrm{OP}$ $(O, \bigcirc)$ and IECP $(\square, \square)$ levels; $B$, epinephrine $(\square, \boldsymbol{\square})$, norepinephrine $(O, \bullet)$ and dopamine $(\triangle, \Delta)$ levels. 
concentration. Theophylline made forskolin more potent in producing loss of epinephrine from the cultures.

Treatment of chromaffin cells with forskolin or theophylline produced the largest changes in OP and IECP levels between 1 and 3 days of exposure (Fig. $4, D$ and $E$ ), with no net increase in total opiate activity between 3 and 5 days of treatment. Although IECP levels in untreated cells declined with time in the experiment shown in Figure $4 E$, other experiments showed that forskolin did increase IECP levels rather than simply preventing their decline (not shown). Increases in dopamine levels and decreases in epinephrine content of cells treated with forskolin or theophylline were also time dependent, and these changes continued, with the exception of forskolin-induced epinephrine losses, throughout the 5 days of exposure to these agents. Forskolin increased the protein content of the cultures over the first 2 days of treatment with no further increase relative to untreated cultures (Fig. $4 F$ ). Theophylline had little effect on the protein content of the cell cultures over the first 2 days but then caused a $40 \%$ loss of protein over the following 3 days.

Exposure of chromaffin cells to forskolin or theophylline for $8 \mathrm{hr}$ increased OP and IECP levels measured at $72 \mathrm{hr}$ after initiation of treatment with little or no effect on the protein content of the cultures (Table VI). Total opiate activity (OPs + IECPs) in cells exposed to forskolin or theophylline for $8 \mathrm{hr}$ increased to $93 \%$ and $66 \%$, respectively, of the levels of total opiate activity in cultures treated for the entire 3-day period. The depletion of cellular catecholamines produced by the 72hr exposure of these agents was prevented by their removal at $8 \mathrm{hr}$. Indeed, catecholamine levels in forskolin- or theophyllinetreated cells ( 8 -hr pulse) were elevated relative to those in similarly washed, untreated cells, but it is unclear whether this represents a stimulation of catecholamine synthesis, as might

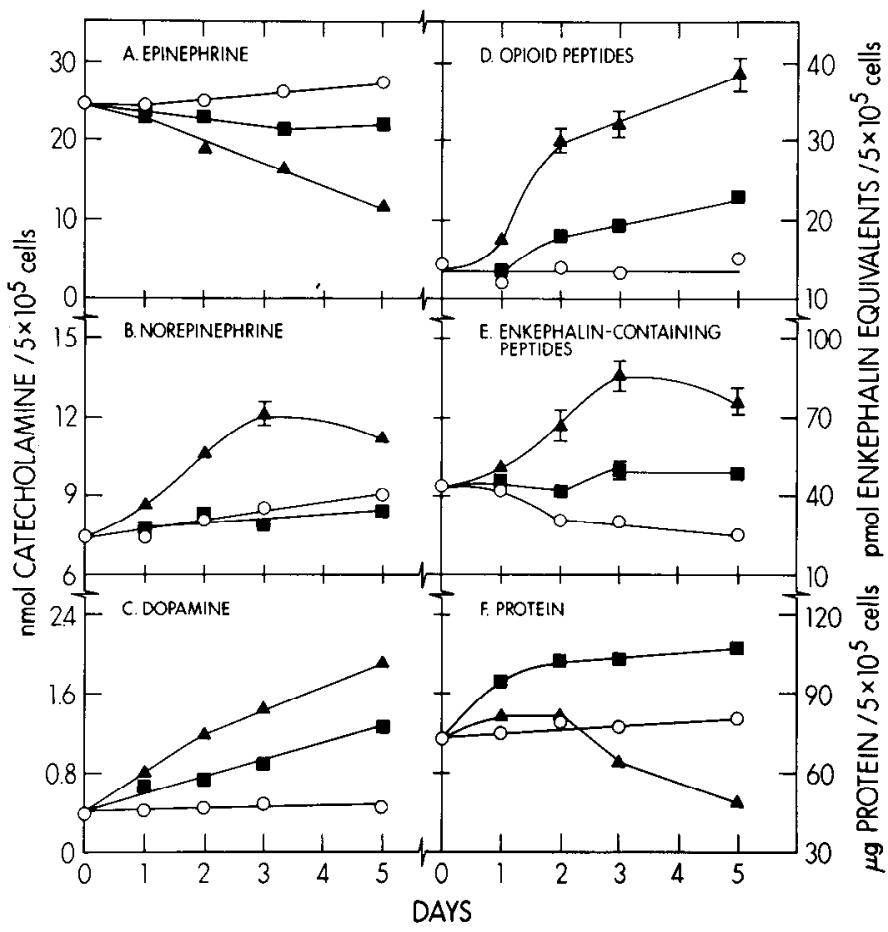

Figure 4. Time dependence of the effects of forskolin and theophylline on chromaffin cell catecholamine, OP, IECP, and protein content. Quadruplicate cultures without additions $(O)$ or with added $5 \mu \mathrm{M}$ forskolin $(\mathbf{\square})$ or $5 \mathrm{mM}$ theophylline $(\boldsymbol{\Delta})$ were harvested at the times indicated and analyzed for catecholamine, OP, and IECP contents. A second, identically treated set of cultures was harvested and analyzed for protein content. Error bars are shown only when larger than the symbol used. be expected following elevated cAMP levels (Waymire et al., 1977), or whether this reflects protection of the cellular catecholamine content of the drug-treated cells during the washing procedure.

\section{Discussion}

\section{Synthesis of OPs and IECPs}

Agents which deplete catecholamine stores and those which should elevate intracellular cAMP levels increase the total opiate activity measured in acetic acid extracts of chromaffin cells. As defined in these studies, total opiate activity in the cells has two components: (1) opiate receptor-active peptides, including Met- and Leu-enkephalin, designated OPs and comprising approximately one-third of the total opiate activity, and (2) peptides, mostly of 5,000 to 20,000 daltons (Lewis et al., 1979; Wilson et al., 1982), that contain enkephalin sequences but are active in an enkephalin radioreceptor assay only following digestion with trypsin and carboxypeptidase $B$, designated IECPs. These two groups of peptides are derived from a common, 30,000-dalton proenkephalin precursor (for review, see Udenfriend and Kilpatrick, 1983). Whether all IECPs are eventually converted to OPs in the chromaffin cell is not yet clear, but enkephalin sequences destined for OPs must be present in the IECP pool at least transiently during processing from the proenkephalin molecule. Hence, an increase in the total opiate activity of chromaffin cells suggests either an increased rate of precursor synthesis or a decreased rate of peptide degradation or secretion. Because cultured chromaffin cells (1) turn over their OP stores slowly (Wilson et al., 1980), (2) exhibit an increased incorporation of radiolabeled amino acids into enkephalins following reserpine treatment (Wilson et al., 1980), (3) increase their OP stores following reserpine treatment by a mechanism sensitive to inhibitors of mRNA translation and ribosomal protein synthesis (Wilson et al., 1981a), and (4) show no change in their basal rate of secretion following treatment with reserpine, tetrabenazine, or forskolin (S. P. Wilson, unpublished results), the increased total opiate activity observed in the present studies most likely results from an increased synthesis of precursor.

Catecholamines. A variety of agents that deplete chromaffin cell catecholamine stores, whether through inhibition of vesicular uptake or inhibition of synthesis, increase total cellular opiate activity. Catecholamines and adrenergic receptor agonists added to the cultures do not increase chromaffin cell opiate activity, nor do catecholamine receptor antagonists block the effect of reserpine on cellular OP stores, demonstrating that extracellular catecholamines do not mediate the regulation of OP and IECP levels in the chromaffin cell. Certain dopamine receptor agonists increase total cellular opiate activity but apparently act by depleting catecholamine stores. The MAO inhibilor tranylcypromine also elevates chromaffin cell OP levels, also apparently by decreasing catecholamine stores, whereas other MAO inhibitors that produce less or no cellular catecholamine depletion fail to increase OP stores. These results suggest that some intracellular pool of catecholamines may trigger an increase in the synthesis of OP precursors.

Determination of the relative contents of intracellular catecholamine pools is very difficult, if not impossible. At least two pools must exist, a cytoplasmic pool and a vesicular pool. The cytoplasm normally contains only $0.01 \%$ of the cellular catecholamines at a concentration of $20 \mu \mathrm{M}$ or less, with the remainder of the catecholamines found in the chromaffin vesicles at a concentration of $0.5 \mathrm{M}$ (Phillips, 1982). Although the concentration of total catecholamines in the cytoplasm should increase following treatment of the cells with inhibitors of amine uptake into vesicles and with MAO inhibitors, inhibitors of catecholamine biosynthesis should decrease the size of this 
TABIE VI

Effects of pulse versus continuous exposure of chromaffin cell to forskolin or theophylline

Eight hours after the addition of forskolin $(5 \mu \mathrm{M})$ or theophylline $(5 \mathrm{mM})$ to chromaffin cell cultures, one-half of the treated and untreated cultures were washed with two changes of culture medium lacking forskolin or theophylline and returned to the $\mathrm{CO}_{2}$ incubator. Bovine serum albumin $(1 \mathrm{mg} / \mathrm{ml})$ was added to the cultures just before washing and to the medium used in the first wash in order to partially protect the cultures from loss of cell contents. All of the cultures ( $n=4$ for each condition) were harvested $72 \mathrm{hr}$ after forskolin or theophylline addition and analyzed for OP, IECP, and catecholamine contents. Protein was measured in a second, identically treated set of cultures.

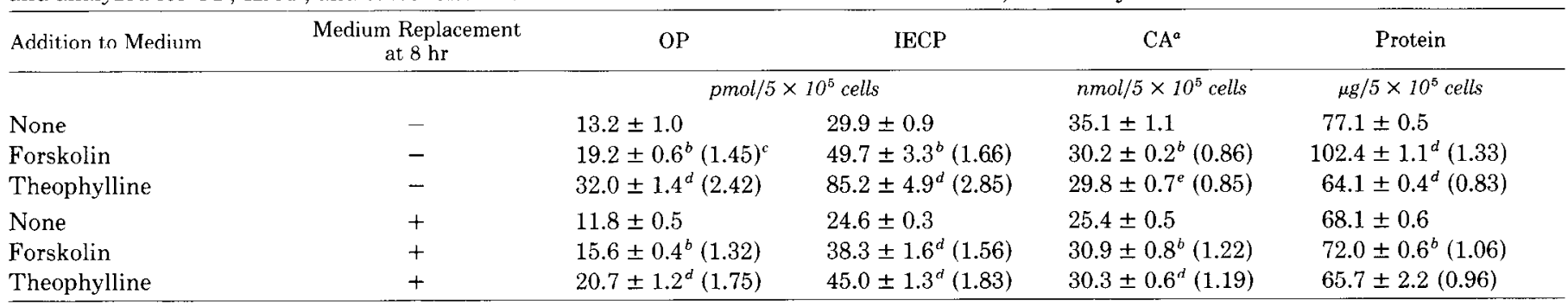

${ }^{a} \mathrm{CA}$, total catecholamines.

${ }^{b} p<0.005$ compared to paired cultures with no additions to medium.

Numbers in parentheses represent the ratio of the value shown to that of corresponding untreated cultures.

${ }^{d} p<0.001$ compared to paired cultures with no additions to medium.

${ }^{e} p<0.01$ compared to paired cultures with no additions to medium.

pool. It is possible, of course, that factors other than catecholamine levels trigger the observed increases in chromaffin cell OP levels. However, the variety of agents that produce increased OP levels subsequent to cellular catecholamine depletion strongly suggests a causal relationship between the two events, although a more complicated alternative mechanism is still possible.

$c A M P$. Although cAMP analogues, activators of adenylate cyclase, and inhibitors of cyclic nucleotide phosphodiesterase can deplete catecholamine stores and increase the total protein content of chromaffin cell cultures, these actions are not prerequisites for the increases in cellular OP and IECP contents produced by these cyclic nucleotide-related drugs. Hence, chromaffin cell cAMP levels may also be important in regulating the synthesis of OPs and IECPs. Recent preliminary reports from other workers have noted similar findings (Schwartz et al., 1983). Although all of the cyclic nucleotide-related agents we tested should elevate cAMP levels in the chromaffin cell or mimic the action of cAMP, we have not ruled out the involvement of other cyclic nucleotides. The high activity of theophylline in increasing total opiate activity in chromaffin cells may result from some action of this drug unrelated to cyclic nucleotides because it does not increase the potency of forskolin in enhancing OP and IECP synthesis. Theophylline and IBMX are antagonists of inhibitory $A_{1}$ and stimulatory $A_{2}$ adenosine receptors coupled to adenylate cyclase; however, maximum effects on these receptors are observed at drug concentrations of less than $1 \mathrm{mM}$ (Londos et al., 1978; Smellie et al., 1979). Methylxanthines at high concentrations also mobilize intracellular calcium stores in both sympathetic neurons (Kuba and Nishi, 1976) and adrenal chromaffin cells (Rahwan et al., 1973). Some combination of these effects of the methylxanthines may explain the results obtained.

Levels of adrenal medullary cAMP are reported to rise following stimulation of the gland via nicotinic acetylcholine receptors in vivo (Guidotti and Costa, 1974); cAMP levels also increase in isolated chromaffin cells following exposure to acetylcholine (Schneider et al., 1979). Therefore, the increase in chromaffin cell OP and IECP stores following elevated cAMP levels observed here may be a homeostatic mechanism for recovery of cellular OP stores following secretion. The relationship between this cAMP-dependent mechanism for elevating chromaffin cell OP stores and that observed following catecholamine depletion, which could also be important in recovery of $\mathrm{OP}$ contents following secretion, is unclear because in preliminary experiments no elevation of cAMP levels was observed in tetrabenazine-treated cells (M. M. Abou-Donia, T. Zimmerman, and O. H. Viveros, unpublished results). Hence, at least two mechanisms for regulating OP and IECP synthesis may exist in chromaffin cells.

Because OPs and IECPs are stored in chromaffin vesicles (Viveros et al., 1979), including those peptides newly formed after treatment with catecholamine-depleting drugs (Wilson et al., 1982), other protein components of chromaffin vesicles should be similarly regulated. Recent studies have shown, however, that the activity of dopamine $\beta$-hydroxylase, a chromaffin vesicle enzyme, does not increase in chromaffin cells treated with reserpine or tetrabenazine (Wilson et al., 1983). Treatment of chromaffin cells with 8-bromo-cAMP, forskolin, or theophylline also fails to alter dopamine $\beta$-hydroxylase activity (Waymire et al., 1977; S. P. Wilson, unpublished results). In contrast, insulin-treated chromaffin cells display a concomitant increase in dopamine $\beta$-hydroxylase activity and IECP content (Wilson et al., 1983). If dopamine $\beta$-hydroxylase activity is a valid marker for the number of vesicles in these cells, then the increased OP and IECP levels observed in the present studies occur without a net increase in the synthesis of vesicles.

\section{Processing of IECPS}

Recent studies on the regulation of OP and IECP levels in chromaffin cells treated with insulin also show an initial increase in IECPs followed 2 days later by an increase in OPs (Wilson et al., 1983), as might be expected for a precursorproduct relationship. However, no such relationship was observed in the present studies. Chromaffin cells treated with catecholamine-depleting agents display an increase in OPs but no change in IECPs during at least the first 3 days of treatment, suggesting that IECPs are more efficiently processed to OPs under these conditions. Because the only known changes in chromaffin cells treated with reserpine or tetrabenazine are decreased vesicular catecholamines and increased vesicular $O P$ contents, these results suggest that catecholamines may inhibit the processing of IECPs to OPs under normal conditions.

Chromaffin cells treated with cyclic nucleotide-related drugs increase IECP and OP levels concomitantly and to a similar extent in most experiments. This suggests that both the rates of synthesis and processing are similarly increased or that processing is not normally rate limiting. In light of the lag between IECP and OP formation in insulin-treated cells, the first alternative seems to be favored. 
Regardless of the detailed mechanism(s) involved in regulation of IECP and OP synthesis and processing, which remain to be elucidated, drugs or physiologic stimuli that alter either the cAMP levels or catecholamine stores of adrenal medullary chromaffin cells are also likely to modulate OP synthesis and storage in these cells.

\section{References}

Anton, A. H., and D. F. Sayre (1962) A study of the factors affecting the aluminum oxide-trihydroxyindole procedure for the analysis of catecholamines. J. Pharmacol. Exp. Ther. 138: 360-375.

Chang, K. -J., and P. Cuatrecasas (1979) Multiple opiate receptors: Enkephalins and morphine bind to receptors of different specificity. J. Biol. Chem. 254: 2610-2618.

Corcoran, J. J., S. P. Wilson, and N. Kirshner (1984) Flux of catecholamines through chromaffin vesicles in cultured bovine adrenal medullary cells. J. Biol. Chem. 259: 6208-6214

Guidotti, A., and E. Costa (1974) A role for nicotinic receptors in the regulation of the adenylate cyclase of adrenal medulla. J. Pharmacol. Exp. Ther. 189: 665-675.

Kilpatrick, D. L., F. H. Ledbetter, K. A. Carson, A. G. Kirshner, R. Slepetis, and N. Kirshner (1980) Stability of bovine adrenal medulla cells in culture. J. Neurochem. 35: 679-692.

Kuba, K., and S. Nishi (1976) Rhythmic hyperpolarization and depolarization of sympathetic ganglion cells induced by caffeine. J. Neurophysiol. 39: 547-563.

Kumakura, K., A. Guidotti, and E. Costa (1979) Primary cultures of chromaffin cells: Molecular mechanisms for the induction of tyrosine hydroxylase mediated by 8-Br-cyclic AMP. Mol. Pharmacol. 16: 865876.

I Lewis, R. V., A. S. Stern, J. Rossier, S. Stein, and S. Udenfriend (1979) Putative enkephalin precursors in bovine adrenal medulla. Biochem. Biophys. Res. Commun. 89: 822-829.

Livett, B. G., P. Boksa, D. M., Dean, F. Mizobe, and M. H. Lindenbaum (1983) Use of isolated chromaffin cells to study basic release mechanisms. J. Auton. Nerv. Syst. 7: 59-86.

Londos, C., D. M. F. Cooper, W. Schlegel, and M. Rodbell (1978) Adenosine analogs inhibit adipocyte adenylate cyclase by a GTPdependent process: Basis for actions of adenosine and methylxanthines on cyclic AMP production and lipolysis. Proc. Natl. Acad. Sci. U. S. A. 75: 5362-5366.

Lowry, O. H., N. J. Rosebrough, A. L. Farr, and R. J. Randall (1951) Protein measurement with the Folin phenol reagent. J. Biol. Chem. 193: 265-275.

McDermed, J. D., G. M. McKenzie, and A. P. Phillips (1975) Synthesis and pharmacology of some 2-aminotetralins. Dopamine receptor agonists. J. Med. Chem. 18: 362-367.

Nagatsu, T., and S. Udenfriend (1972) Photometric assay of dopamine$\beta$-hydroxylase activity in human blood. Clin. Chem. 18: 980-983.

Phillips, J. H. (1982) Dynamic aspects of chromaffin granule structure. Neuroscience 7: 1595-1609.

Pletscher, A. (1977) Effect of neuroleptics and other drugs on monoamine uptake by membranes of adrenal chromaffin granules. Br. J. Pharmacol. 59: 419-424.

Rahwan, R. G., J. L. Borowitz, and T. S. Miya (1973) The role of intracellular calcium in catecholamine secretion from the bovine adrenal medulla. J. Pharmacol. Exp. Ther. 184: 106-118.

Rossier, J., D. M. Dean, B. G. Livett, and S. Udenfriend (1981) Enkephalin congeners and precursors are synthesized and released by primary cultures of adrenal chromaffin cells. Life Sci. 28: 781789 .

Schneider, A. S., H. T. Cline, and S. Temaire (1979) Rapid rise in cyclic GMP accompanies catecholamine secretion in suspensions of isolated adrenal chromaffin cells. Life Sci. 24: 1389-1394.

Schultzberg, M., J. M. Lundberg, T. Hokfelt, L. Terenius, J. Brandt, R. P. Elde, and M. Goldstein (1978) Enkephalin-like immunoreactivity in gland cells and nerve terminals of the adrenal medulla. Neuroscience 3: 1169-1186.

Schwartz, J. P., T. T. Quach, P. Panula, and E. Costa (1983) Regulation of expression of proenkephalin mRNA in cultured chromaffin cells of bovine adrenal. Soc. Neurosci. Abstr. 9: 745.

Seamon, K. B., W. Padgett, and J. W. Daly (1981) Forskolin: Unique diterpene activator of adenylate cyclase in membranes and in intact cells. Proc. Natl. Acad. Sci. U. S. A. 78: 3363-3367.
Smellie, F. W., C. W. Davis, J. W. Daly, and J. N. Wells (1979) Alkylxanthines: Inhibition of adenosine-elicited accumulation of cyclic AMP in brain slices and of brain phosphodiesterase activity. Life Sci. 24: 2475-2482.

Tomlinson, D. R. (1977) The mode of action of tetrabenazine on peripheral noradrenergic nerves. Br. J. Pharmacol. 61: 339-344.

Udenfriend, S., and D. L. Kilpatrick (1983) Biochemistry of the en kephalins and enkephalin-containing peptides. Arch. Biochem. Biophys. 221 : 309-323.

Varndell, I. M., F. J. Tapia, J. DeMey, R. A. Rush, S. R. Bloom, and J. M. Polak (1982) Electron immunocytochemical localization of enkephalin-like material in catecholamine-containing cells of the carotid body, the adrenal medulla, and in pheochromocytomas of man and other mammals. J. Histochem. Cytochem. 30:682-690.

Viveros, O. H., E. J. Diliberto, Jr., E. Hazum, and K. -J. Chang (1979) Opiate-like materials in the adrenal medulla: Evidence for storage and secretion with catecholamines. Mol. Pharmacol. 16: 11011108.

Viveros, O. H., E. J. Diliberto, Jr., E. Hazum, and K. -J. Chang (1980) Enkephalins as possible adrenomedullary hormones: Storage, secretion and regulation of synthesis. Adv. Biochem. Psychopharmacol. 22: 191-204.

Waggoner, W. G., J. McDermed, and H. J. Leighton (1980) Presynaptic regulation of tyrosine hydroxylase activity in rat striatal synaptosomes by dopamine analogs. Mol. Pharmacol. 18: 91-99.

Waymire, J. C., K. G. Waymire, R. Boehme, D. Noritake, and J. Wardell (1977) Regulation of tyrosine hydroxylase by cyclic $3^{\prime}: 5^{\prime}$ adenosine monophosphate in cultured neuroblastoma and cultured dissociated bovine adrenal chromaffin cells. In Structure and Function of Monoamine Enzymes, E. Usdin, N. Weiner, and M. B. H. Youdim, eds., pp. 327-363, Marcel Dekker, New York.

Waymire, J. C., W. F. Bennett, R. Boehme, L. Hankins, K. GilmerWaymire, and J. W. Haycock (1983) Bovine adrenal chromaffin cells: High yield purification and viability in suspension culture. J. Neurosci. Methods 7: 329-351.

Wilson, S. P., and N. Kirshner (1983a) Calcium-evoked secretion from digitonin-permeabilized adrenal medullary chromaffin cells. J. Biol. Chem. 258: 4994-5000.

Wilson, S. P., and N. Kirshner (1983b) Effects of ascorbic acid, dexamethasone, and insulin on the catecholamine and opioid peptide stores of cultured adrenal medullary chromaffin cells. J. Neurosci. 3 : 1971-1978.

Wilson, S. P., and N. Kirshner (1983c) Preparation and maintenance of adrenal medullary chromaftin cell cultures. Methods Enzymol. 103: 305-342.

Wilson, S. P., and O. H. Viveros (1981) Primary culture of adrenal medullary chromaffin cells in a chemically defined medium. Exp. Cell Res. 133: 159-169.

Wilson, S. P., K. -J. Chang, and O. H. Viveros (1980) Synthesis of enkephalins by adrenal medullary chromaffin cells: Reserpine increases incorporation of radiolabeled amino acids. Proc. Natl. Acad. Sci. U. S. A. $77: 4364-4368$

Wilson, S. P., M. M. Abou-Donia, K. -J. Chang, and O. H. Viveros (1981a) Reserpine increases opiate-like peptide content and tyrosine hydroxylase aclivily in adrenal medullary chromaffin cells in culture. Neuroscience 6: 71-79.

Wilson, S. P., K. -J. Chang, and O. H. Viveros (1981b) Opioid peptide synthesis in bovine and human adrenal chromaffin cells. Peptides 2 (Suppl. 1): 83-88.

Wilson, S. P., K. -J. Chang, and O. H. Viveros (1981c) Opioid peptide synthesis in chromaffin and human pheochromocytoma cells. Trans. Am. Soc. Neurochem. 12: 204.

Wilson, S. P., L. X. Cubeddu, K. -J. Chang, and O. H. Viveros (1981d) Met-enkephalin, leu-enkephalin and other opiate-like peptides in human pheochromocytoma tumors. Neuropeptides 1: 273-281.

Wilson, S. P., K. -J. Chang, and O. H. Viveros (1982) Proportional secretion of opioid peptides and catecholamines from adrenal chromaffin cells in culture. J. Neurosci. 2: 1150-1156.

Wilson, S. P., O. H. Viveros, and N. Kirshner (1983) Relationship between opioid peptide levels and storage vesicle synthesis in adrenal medullary chromaffin cells. Soc. Neurosci. Abstr. 9: 387.

Yang, H. -Y. T., A. M. Digiulio, W. Fratta, J. S. Hong, E. A. Majane, and E. Costa (1980) Enkephalin in bovine adrenal gland: Multiple molecular forms of [ $\mathrm{Met}^{5}$ ]enkephalin immunoreactive peptides. Neuropharmacology 19: 209-215. 